Thorax, 1980, 35, 347-350

\title{
Cardiac and respiratory responses to exercise in adolescent idiopathic scoliosis
}

\section{J M SHNEERSON}

From the Department of Respiratory Physiology, Cardiothoracic Institute, Brompton Hospital, London

ABSTRACT Twenty girls, aged 11-15 years, with adolescent idiopathic scoliosis were studied before spinal fusion was performed. Each underwent a range of lung function tests and a standardised progressive exercise test on a bicycle ergometer. The resting lung function tests showed reduced peak flow rates, lung volumes, and maximum voluntary ventilation. The maximum oxygen uptake was slightly diminished but maximum exercise ventilation was normal. The latter was achieved by using a greater than normal fraction of the vital capacity in tidal breathing while exercising. Mild hyperventilation during submaximal exercise and a trend towards an exercise tachycardia with increasing body weight were observed.

Hippocrates was the first to record that hunchbacks were "affected with difficulty of breathing and hoarseness", and Hutchinson ${ }^{1}$ demonstrated that their vital capacity could be much reduced. However, only recently has their response to exercise been studied, ${ }^{2}$ and pulmonary hypertension, hyperventilation, and limited maximal exercise ventilation and maximal oxygen uptake demonstrated in adult scoliotics. There have been few previous reports of cardiac or respiratory responses to exercise in adolescent scoliotics, and the assessment of fitness, for instance for spinal fusion, has depended on clinical judgment and resting lung function tests. In this study patients with adolescent idiopathic scoliosis underwent a standardised exercise test in order to assess their cardiac and respiratory function and to compare it with the findings in adults with scoliosis.

\section{Methods}

Twenty successive girls referred with adolescent idiopathic scoliosis requiring spinal fusion were studied. Their ages ranged from 11 - 15 years (mean $13 \cdot 7, \mathrm{SD}=1 \cdot 2$ ). None had any cardiac or respiratory disease complicating the scoliosis. The angle of scoliosis was determined by the method of Cobb. ${ }^{4}$ It ranged from 40 to $84^{\circ}$ (mean $62^{\circ}, \mathrm{SD}=11^{\circ}$ ). Their mean weight was $47 \cdot 5 \mathrm{~kg}(\mathrm{SD}=6 \cdot 1)$, height $159 \cdot 3 \mathrm{~cm}(\mathrm{SD}=7 \cdot 1)$, and arm span $165.6 \mathrm{~cm}$ $(\mathrm{SD}=5 \cdot 8)$.

Their peak flow rate (PEFR) was measured with a Wright peak flow meter, the forced expiratory

Address for reprint requests: Dr J M Shneerson, Senior Registrar, Westminster Hospital, Horseferry Road, London SW1. volume in one second $\left(\mathrm{FEV}_{1}\right)$ and forced vital capacity (FVC) with a dry spirometer (Vitalograph), and their maximum voluntary ventilation (MVV) with a low resistance nine-litre wet spirometer (PK Morgan).

Exercise was performed while sitting on an electrically - braked bicycle ergometer (Lode). The inspiratory minute volume was measured by a Parkinson Cowan CD4 dry gas meter with an electrical output to a direct-writing ink-jet recorder (Mingograf 81). The gas meter was calibrated with a sinusoidal pump operating at various stroke volumes and frequencies. The gas meter was connected by wide-bore tubing to a low resistance two-way respiratory valve (PK Morgan 71522) with a dead space of $60 \mathrm{ml}$. The resistance of the system to inspiration was $0.43 \mathrm{~cm} \mathrm{H}_{2} \mathrm{O}$ at $10 \mathrm{l} / \mathrm{min}$ and $0.95 \mathrm{~cm} \mathrm{H}_{2} \mathrm{O}$ at $70 \mathrm{l} / \mathrm{min}$. The expired gas passed through wide-bore connecting tubing to a mixing chamber of 7.81 capacity containing an electrically driven fan. A sample of the mixed expired gas was dried with magnesium perchlorate and passed through a paramagnetic Servomex OA 150 oxygen analyser, and an infrared absorption $\mathrm{CO}_{2}$ analyser (URAS 4). The Servomex response was linear over the range $14-21 \% \mathrm{O}_{2}$ and the URAS 4 over the range $0-5 \% \mathrm{CO}_{2}$. The $95 \%$ response times of both to a square wave of gas leaving the mixing chamber were 4 seconds. Both machines were connected electrically to the Mingograf and were recalibrated before and after each test.

The patients were made familiar with the apparatus on the day before the tests. They rested on the ergometer until their inspired ventilation, 
mixed expired gas composition, and heart rate were steady. They then began pedalling, initially at a work rate of 15 watts, The work rate was increased by 15 watts each minute and the patients were encouraged to keep exercising for as long as possible. There were no complications of the procedure.

The regression coefficients of minute ventilation $(\dot{V} E)$ and heart rate (HR) on oxygen uptake $\left(\dot{\mathrm{V}}_{2}\right)$ were calculated over the linear part of the relationships by the least squares method. The $\dot{V}_{E}$ and HR responses were expressed as maximal values(V̈E max; $\mathrm{HR}$ max) and at interpolated values of $\mathrm{VO}_{2}$ of $0.751,1.01$, and 1.51 ( V̇e 0.75 , V̇e 1.0 , V̇e 1.5 ; HR $0 \cdot 75$, HR $1 \cdot 0$, HR $1 \cdot 5) .{ }^{5} 6$

\section{Results}

PEAK FLOW RATE, SPIROMETRY, AND MAXIMUM VOLUNTARY VENTILATION

The PEFR, FEV 1 , and FVC results are displayed in table 1 . The observed values were all significantly $(p<0.01)$ less than predicted from their height. ${ }^{7}$ The

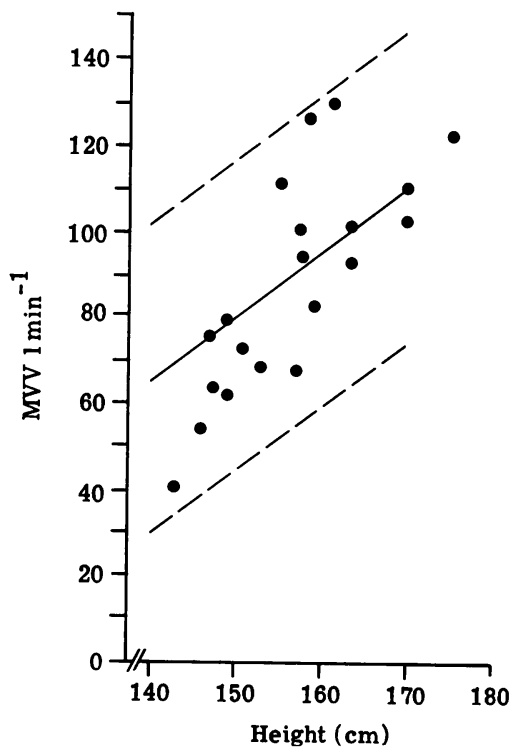

Fig 1 Relationship between $M V V$ and height showing that the MVV of all 20 subjects fell within two standard deviations of normal (broken lines).

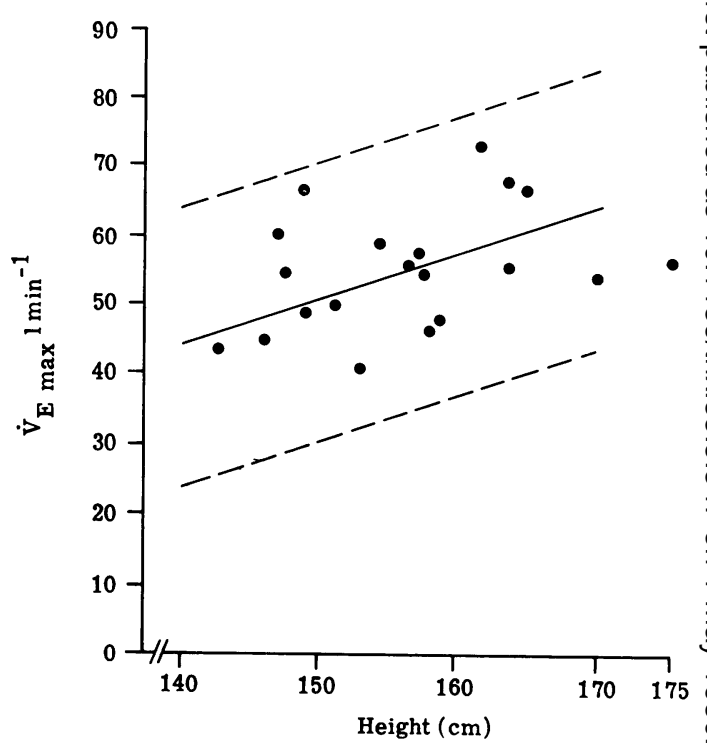

Fig 2 Relationship between $\dot{V} E$ max and height showing that $\dot{V} E$ max of all 20 subjects fell within two standard deviations of normal (broken lines).

observed MVV values were all within two standard deviations of normal $^{8}$ (fig 1 ).

MAXIMUM OXYGEN UPTAKE

Maximum oxygen uptake $\left(\dot{\mathrm{V}}_{2}\right.$ max) ranged from 1.07 to $2.451 \mathrm{~min}^{-1}$ (mean $1 \cdot 60, \mathrm{SD}=0 \cdot 37$ ). Corrected for body weight the mean value was $33.8 \mathrm{ml}$ $\mathrm{kg}^{-1} \mathrm{~min}^{-1}$ (range 26.7-50.1, $\mathrm{SD}=5 \cdot 6$ ) which is slightly below the normal figure for girls of $40 \mathrm{ml}$ $\mathrm{kg}^{-1} \min ^{-1}{ }^{9}$

MAXIMUM EXERCISE VENTILATION

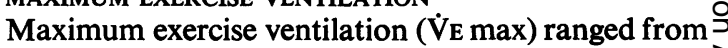
41.09 to $76 \cdot 341 \mathrm{~min}^{-1}$ (mean $\left.56 \cdot 15, \mathrm{SD}=9 \cdot 95\right)$. The mean ratio of $\dot{V}_{E} \max$ to MVV (the dyspnoeic index was normal at $0 \cdot 65$. The individual values for VE $\max \stackrel{N}{N}$ were all within normal limits for girls ${ }^{8}\left(\mathrm{fig}_{4} \mathbf{2}\right)$.

MINUTE VENTILATION

The submaximal minute ventilation $(\dot{\mathrm{V} E})$ at $\dot{\mathrm{V}}_{2}$ of $0 \cdot 75,1.0$, and $1.51 \mathrm{~min}^{-1}$ is shown in fig 3 . The values?

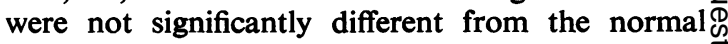

Table 1 Peak flow rates and spirometry

\begin{tabular}{|c|c|c|c|c|c|c|}
\hline$n=20$ & $\begin{array}{l}P E F R \\
\left(l \text { min }^{-1}\right)\end{array}$ & $\begin{array}{l}\text { PEFR } \\
\text { (\% predicted })\end{array}$ & $\begin{array}{l}F E V_{1} \\
(l)\end{array}$ & $\begin{array}{l}F E V_{1} \\
(\% \text { predicted })\end{array}$ & $\begin{array}{l}F V C \\
(I)\end{array}$ & $\begin{array}{l}F V C \\
\text { (\% predicted) }\end{array}$ \\
\hline $\begin{array}{l}\text { Range } \\
\text { Mean } \\
\text { SD }\end{array}$ & $\begin{array}{l}220-480 \\
378 \\
70\end{array}$ & $\begin{array}{l}54-104 \\
84 \cdot 9 \\
12 \cdot 6\end{array}$ & $\begin{array}{l}1 \cdot 30-3 \cdot 10 \\
2 \cdot 32 \\
\cdot 53\end{array}$ & $\begin{array}{l}51-103 \\
78 \cdot 2 \\
14 \cdot 3\end{array}$ & $\begin{array}{l}1 \cdot 40-3 \cdot 50 \\
2.64 \\
.59\end{array}$ & $\begin{array}{l}52-112 \\
78 \cdot 8 \\
14 \cdot 8\end{array}$ \\
\hline
\end{tabular}




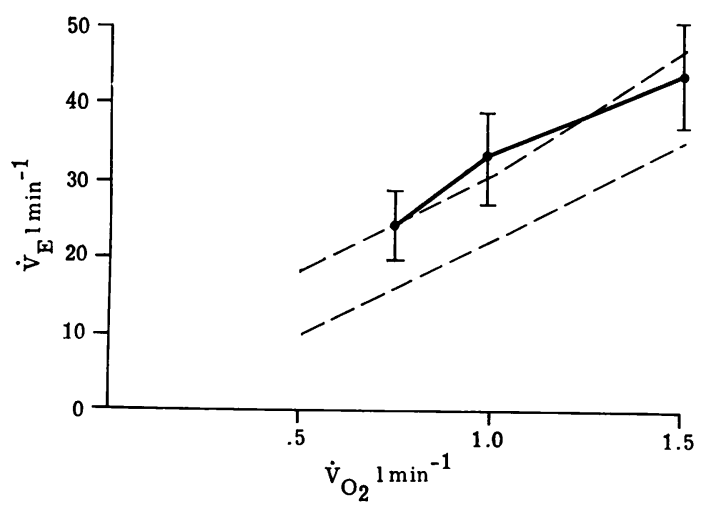

Fig 3 Submaximal ventilatory response during exercise. The broken lines represent the normal limits. $\mathbf{1 0}$

group. ${ }^{10}$ The intercept on the $y$ axis of the regression line of $\dot{\mathrm{VE}}$ on $\mathrm{Vo}_{2}$ was normal (mean $=-1.61 \mathrm{~min}^{-1}$, $\mathrm{SD}=3 \cdot 3$; normal:-mean $\left.=+0.71 \mathrm{~min}^{-1}, \mathrm{SD}=1 \cdot 7\right)$. However the regression coefficient of $\dot{\mathrm{VE}}$ on $\dot{\mathrm{VO}}_{2}$ was above normal (mean $=33 \cdot 6, \mathrm{SD}=6 \cdot 6$; normal:mean $=26 \cdot 9, \mathrm{SD}=2 \cdot 7)$, indicating that slight hyperventilation was occurring.

\section{MAXIMAL TIDAL VOLUME AND RESPIRATORY}

FREQUENCY

Maximal tidal volume (VT max) ranged from 0.96 to 2.671 (mean $1 \cdot 70, \mathrm{SD}=0.61$ ). $\mathrm{VT} \max / \mathrm{VC}$ ranged from 0.41 to 0.90 . The mean value was 0.67 $(\mathrm{SD}=0.13$ ), which is considerably above the normal of 0.50 .11 The mean maximal respiratory frequency was normal $\left(45.7 \mathrm{~min}^{-1}, \mathrm{SD}=13.0\right)$.

\section{HEART RATE}

The heart rate increased linearly with $\dot{\mathrm{Vo}}_{2}$ throughout exercise. The mean HR max was $183.5 \mathrm{~min}^{-1}$ $(\mathrm{SD}=13 \cdot 2)$. The submaximal values of $\mathrm{HR}$ at $\dot{\mathrm{V}} \mathrm{O}_{2}$ of $0.75,1.0$, and $1.51 \mathrm{~min}^{-1}$ were corrected for

Table 2 Heart rate response during exercise compared with normal ${ }^{10}$

\begin{tabular}{|c|c|c|c|c|c|}
\hline & \multirow[t]{2}{*}{$\begin{array}{l}\text { Weight } \\
(k g)\end{array}$} & \multirow[t]{2}{*}{$n$} & \multicolumn{2}{|c|}{$\begin{array}{l}\text { Observed value } \\
\text { (beats min-1) }\end{array}$} & \multirow[t]{2}{*}{$\%$ predicted } \\
\hline & & & Mean & $S D$ & \\
\hline HR 0.75 & $\begin{array}{l}36-45 \\
46-55 \\
56-65\end{array}$ & $\begin{array}{l}8 \\
8 \\
4\end{array}$ & $\begin{array}{l}133 \cdot 1 \\
127 \cdot 6 \\
130 \cdot 0\end{array}$ & $\begin{array}{r}9.4 \\
17.6 \\
10 \cdot 4\end{array}$ & $\begin{array}{l}101 \\
108 \\
124\end{array}$ \\
\hline HR 1.0 & $\begin{array}{l}36-45 \\
46-55 \\
56-65\end{array}$ & $\begin{array}{l}8 \\
8 \\
4\end{array}$ & $\begin{array}{l}154 \cdot 9 \\
142 \cdot 0 \\
145 \cdot 5\end{array}$ & $\begin{array}{r}10 \cdot 2 \\
19 \cdot 2 \\
9 \cdot 7\end{array}$ & $\begin{array}{r}99 \\
104 \\
121\end{array}$ \\
\hline HR 1.5 & $\begin{array}{l}36-45 \\
46-55 \\
56-65\end{array}$ & $\begin{array}{l}2 \\
6 \\
4\end{array}$ & $\begin{array}{l}163 \cdot 0 \\
162 \cdot 3 \\
177 \cdot 5\end{array}$ & $\begin{array}{r}2 \cdot 8 \\
20 \cdot 7 \\
9.9\end{array}$ & $\begin{array}{r}85 \\
99 \\
122\end{array}$ \\
\hline
\end{tabular}

body weight and compared to the normal values of Jones et $\mathbf{l}^{10}$ (Table 2). The ratio of the observed/ predicted values at each level of $\mathrm{Vo}_{2}$ increased with increasing weight. It exceeded $1 \cdot 2$ for each $\dot{\mathrm{Vo}}_{2}$ level in the heaviest group of subjects (56-65 kg).

\section{Discussion}

The resting lung function tests confirmed the diminished PEFR, FEV 1, FVC, and MVV that are characteristic of severe scoliosis. ${ }^{12}$ The results obtained in this study have been compared with normal adolescent girls using the observed height to predict the normal values. Although scoliosis shortens the stature, the use of arm $\operatorname{span}^{13}$ is also imperfect as adolescent idiopathic scoliotics have an abnormally large span. ${ }^{14}$ However, any error incurred would tend to underestimate the severity of the restrictive defect.

The type of progressive exercise test that these subjects carried out has been widely used and, as long as conditions are carefully standardised, ${ }^{15}$ it gives repeatable results. ${ }^{16}$ The response to exercise of these adolescent girls shows several differences both from age- and sex-matched normal subjects and from adult scoliotics. Their $\dot{\mathrm{Vo}}_{2} \max$ was $15.5 \%$ below the predicted value. The measurement of $\dot{\mathrm{Vo}}_{2}$ max is technically difficult since it depends on the motivation of the subject to exercise until his physical limit, the type of exercise performed, and the details of the exercise procedure. For these reasons the slightly low value obtained in this study may not be physiologically significant. In any case it is of a smaller degiee than that seen in adult scoliotics with a similar severity of deformity. ${ }^{3}$ The values obtained for $\dot{\mathrm{Vo}}_{2} \max$ were not correlated with VE max. This contrasts with adult scoliotics in whom the low $\dot{V}$ max probably limits $\mathrm{Vo}_{2}$ max; in the present study $\dot{V} E$ max was normal and exercise was able to proceed until, as is normal, it was limited by circulatory factors.

Hyperventilation during submaximal exercise was not detected by analysing the results at $\dot{\mathrm{V}}_{2}$ values of $0.75,1.0$, and $1.51 \mathrm{~min}^{-1}$. However the mean regression coefficient of $\dot{\mathrm{VE}}$ on $\dot{\mathrm{VO}}_{2}$ was $33.6 \mathrm{com}$ pared with the normal value of 26.9 . Thus some hyperventilation at submaximal exercise is probably occurring as it does in adult scoliotics. ${ }^{3}$

Interestingly, the pattern of breathing during maximal exercise was abnormal in the same way as seen in adult scoliotics. ${ }^{3}$ The maximal respiratory frequency was normal but the maximal tidal volume, expressed as a percentage of the vital capacity, was increased. By using a high percentage of the vital capacity the tidal volume is preserved despite the diminution in vital capacity (table 1 ). 
The heart rate increased linearly with $\dot{V}_{2}$. When it was corrected for body weight an interesting trend of rise in observed/predicted ratio with increasing weight was noted. This is not seen in adult scoliotics. ${ }^{3}$ It could indicate that some of these adolescents develop a true exercise tachycardia and that they, therefore, take less exercise and become obese. Alternatively, the heavier, more obese group may simply be less physically fit because of lack of exercise and develop tachycardia during exercise because of this.

Thus these scoliotics, studied within a few years of the onset of their deformity, have acquired the same type of restrictive ventilatory defect and pattern of breathing during exercise as adult scoliotics. Their maximum oxygen uptake is slightly diminished, but much less so than in adults. Their maximum exercise ventilation is still normal, and none had any symptoms of limitation of exercise tolerance. A longitudinal study is required to determine at what later stage in their development the full picture of the abnormalities of the adult scoliotic develop.

I would like to thank Mr M Edgar for allowing me to study patients under his care, Dr F J Prime for his constant help and advice, and Mrs J MacGuigan for typing the manuscript. The work was carried out while I was Clinical Lecturer in the Department of Respiratory Physiology, Cardiothoracic Institute, Brompton Hospital, London and was supported by grants from the Research Committee of the Brompton Hospital and by Boehringer Ingelheim Ltd.

\section{References}

1 Hutchinson J. Contributions to vital statistics obtained by means of a pneumatic apparatus for valuing the respiratory powers with relation to health. J Statist Soc London 1844; 7:193-212.

2 Shneerson JM. Pulmonary artery pressure in thoracic scoliosis during and after exercise while breathing air and pure oxygen. Thorax 1978; 33: 747-54.

3 Shneerson JM. The cardiorespiratory response to exercise in thoracic scoliosis. Thorax 1978; 33: 457-63.

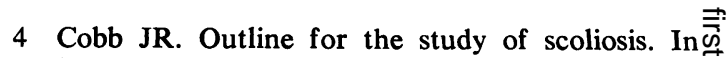
instructional course lectures. Am Acad Orth Surgo 1948; 5:261-75.

5 Cotes JE. Relationships of oxygen consumption, $\frac{\overline{\bar{D}}}{}$ ventilation, and cardiac frequency to body weight $\widehat{\Phi}$ during standardised submaximal exercise in normal subjects. Ergonomics 1969; 12:415-27. क

6 Spiro SG, Juniper E, Bowman P, Edwards RHT. $\overrightarrow{0}$ An increasing work rate test for assessing the physiological strain of submaximal exercise. Clin $\vec{\omega}$ Sci Mol Med 1974; 46:191-206.

7 Godfrey S, Kamburoff PL, Nairn JR. Spirometry, lung volumes and airway resistance in normal children aged 5-18 years. Br J Dis Chest 1970; 64:15-24.

8 Godfrey S. Growth and development of cardiopulmonary responses to exercise. In: Davis JA, 응 Dobbing J (eds). Scientific Foundations of Paedi-atrics. London: Heinemann, 1974: 271-80.

9 Davies CTM, Barnes C, Godfrey S. Body com position and maximal exercise performance in $\overrightarrow{0}$ children. Hum Biol 1972; 44:195-214.

10 Jones NL, Campbell EJM, Edwards RHT Robertson DG. Clinical exercise testing. Philadelphia: W B Saunders, 1975.

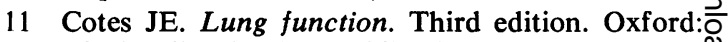
Blackwell Scientific Publications, 1975.

12 Weber B, Smith JP, Briscoe WA, Friedman SA, $\stackrel{\mathbb{Q}}{\mathbb{Q}}$ King TKC. Pulmonary function in asymptomatic $\vec{F}$ adolescents with idiopathic scoliosis. Am RevS Respir Dis 1975; 111:389-97.

13 Johnson BE, Westgate HD. Methods of predict ing vital capacity in patients with thoracic scoliosis. J Bone Joint Surg 1970; 52A:1433-9.

14 Burwell RG, Dangerfield PH, Vernon CL Anthropometry and scoliosis. In: Zorab PA (ed) Scoliosis. Proceedings of a Fifth Symposium London: Academic Press, 1977: 123-63.

15 Taylor HL, Wang Y, Rowell L, Blomqvist G윽 The standardisation and interpretation of submaximal and maximal tests of working capacity Pediatrics 1963; 32:703-22.

16 Cotes JE, Allsopp D, Sardi F. Human cardio pulmonary responses to exercise: comparisons between progressive and steady state exercise? betwen arm and leg exercise, and between sub 0 jects differing in body weight. $Q J$ Exp Physiow 1969; 54:211-22. 